\title{
Editorial
}

\section{Knowledge as coordination of action}

'Knowledge' is rapidly becoming a new keyword in the world of economics, business and management. The 'information age' has not lasted that long. Management Information Systems (MIS) are inadequate and Information Technologies (IT) have fruited. We are all starting to have enough of information and seem to be increasingly in need and short of knowledge.

So, the knowledge stage appears to be settling in: knowledge industries, knowledge workers, knowledge as capital, knowledge support systems, Chief Knowledge Officer (CKO), knowledge production, organizational learning, hyperknowledge, and so on.

Companies are investing in knowledge, nations are building knowledge infrastructures, economies are thriving on brains and becoming increasingly indifferent to muscle. We are working smarter, not harder.

It can now be demonstrated that the richest nations are those well equipped in knowledge and human capital, while the poorest have natural resources only. Natural resources are no resources without knowledge. Built capital is useless without knowledge. Money cannot do a thing without knowledge - except paying for it.

All this is probably good and welcome. Only a few would argue against increasing knowledge, living in a knowledge society or continually striving for knowledge enhancement. Many have argued against information, especially wrong information or too much of information.

Although it is quite easy to say that there is too much information, it is rather difficult to even contemplate that there could be too much knowledge. Just try to say: "I know too much" or "There should be less knowledge" or "Too much knowledge is bad". Compared to data or information, knowledge has much more positive connotation. Knowledge is good. So what is bad about it?

The bad thing is that too many people, experts and laymen alike, treat knowledge as some sort of higher-level information; extended, synthetic, advanced, tacit, etc., but still information.
Although information is an enhanced form of data, knowledge is not an enhanced form of information.

It is quite clear, even on an intuitive level, that knowledge is not the same thing as information, not even a form of information. It cannot be handled as information, does not have the same uses and will resist any simplistic or expedient methodological transfers from information systems to 'knowledge systems'.

It is therefore most important to define knowledge in a distinct, appealing and operational way. Simply calling or labeling some forms of information as 'knowledge' will not make it knowledge, even if repeated.

Our language is not very precise on this matters because there was never a great need for drawing such distinction. So, we may characterize a piece of information, like "The productivity at Toyota is 132 cars per employee per year", as knowledge: do you know it, do you know of it, how do you know it, he has that knowledge, she does not know it, and so on. That of course does not make that information transformed into knowledge by any means.

We can also 'learn' such a piece of information, we can become quite knowledgeable about vast amounts of information or even have knowledge of how to bake bread or to milk cows.

There: those last two examples do not fit. Baking bread and milking cows is not information but 'true' knowledge, although some information could be quite helpful to have among the inputs before demonstrating knowledge through action.

'Knowledge' of information can be demonstrated through a statement, recall or display. Knowledge itself can only be demonstrated through action.

There is no other way of demonstrating my knowledge of baking bread than by baking it. I know how to write books because I write them. I cannot claim knowing how to milk a cow by a mere statement or by writing a book. I do not know how to manage a company but I can give you plenty information on that subject. 
The expression "He wrote the book" does not prove knowledge of anything else than of writing books combined with a plenty of information. That does not mean that a good milkmaid could not write a book on milking cows. In many areas they often do.

So what is knowledge?

Knowledge is purposeful coordination of action. Achieving its purpose is its sole proof or demonstration. Its quality can be judged from the quality of its attainment (its product) or even from the quality of the coordination (its process), especially when uncontrollable factors interfere.

\section{Is there a theory of knowledge?}

A useful theory of knowledge comes from C.I. Lewis's system of conceptualistic pragmatism, rooted in the thought of Peirce, James and Dewey. Both knowledge and 'truth' are necessarily social.

We are able to bring our world forth only through the operations of separation and integration of sensory data. Knowledge, in order to be shared and validated through a social intercourse, must be expressed in words that are further interrelated in language. We use language to coordinate our actions in a social domain.

Since knowledge coordinates human action then socially divided or distributed knowledge can fulfill its coordinating function only through some form of language.

Lewis captured the social dimension of knowledge through his term community of action. Congruity of behavior and consensual human cooperation are the ultimate tests of shared knowledge.

Consensual cooperation of human beings does not stem from some vague identity of their psychological perception, experience or compatible worldviews. It stems from their inherent tendency to action, basic similarity of needs, and shared organismic structure.

\section{Knowledge as a process}

Human knowledge thus cannot refer to static descriptions or 'captures' of facts, things or objects 'out there', outside us, in the 'objective world'. Such 'captures' could be labeled as data or information, but they do not constitute knowledge because they describe separate objects and not their relationships. Knowledge is about relating descriptions of objects into coherent complexes. The relationships among objects are not simply 'out there' to be captured, but are being continually constructed, deconstructed and re-established by the knower.

Knowledge thus cannot be separated from the process of knowing (establishing relationships). Knowledge and knowing are identical: knowledge is a process.

What is meant when we say that somebody knows or possesses knowledge? We imply that we expect one to be capable of coordinated action towards some goals or objectives. Coordinated action is the test of possessing knowledge. Knowledge without action reduces to simple information or data. Maturana and Varela put it quite succinctly: All doing is knowing, and all knowing is doing.

Vast repositories of data and information (data banks, encyclopedias, "wise men on the mountain") are only passive recordings of 'raw material' of knowledge. Only coordinated human action, i.e., process of relating such components into coherent patterns, which turn out to be successful in achieving goals and purposes, qualifies as knowledge.

Among the myriads of possible postulated relationships among objects, only some result in a coordinated action. Every act of knowing brings forth a world. We 'bring forth' a hypothesis about the relationships and test it through action; if we succeed in reaching our goal: we know.

Bringing forth a world of coordinated action is human knowledge.

Separation of knowing from doing (knowledge from action) in the sense of 'some know and others act', like the separation of managers (coordinators) from the doers (workers), is a gaping and selfinflicted 'wound' of modern management. This gap is further amplified by the fashionable distinction between action-centered and 'intellective' skills, or between automation (action) and informating (description of action), or even between body and mind. Such dilemmas are artificial: knowledge cannot be separated from doing.

Knowledge as an effective action enables a living (human) being to persist in its coordinated existence in a specific environment from which it continually brings forth its own world of action. All knowing is coordinated action by the knower and therefore depends on the 'structure' of the knower. The way knowledge can be brought forth in doing depends on the nature of 'doing' as it is implied by the organization of the knower and his circumstance (working environment). 


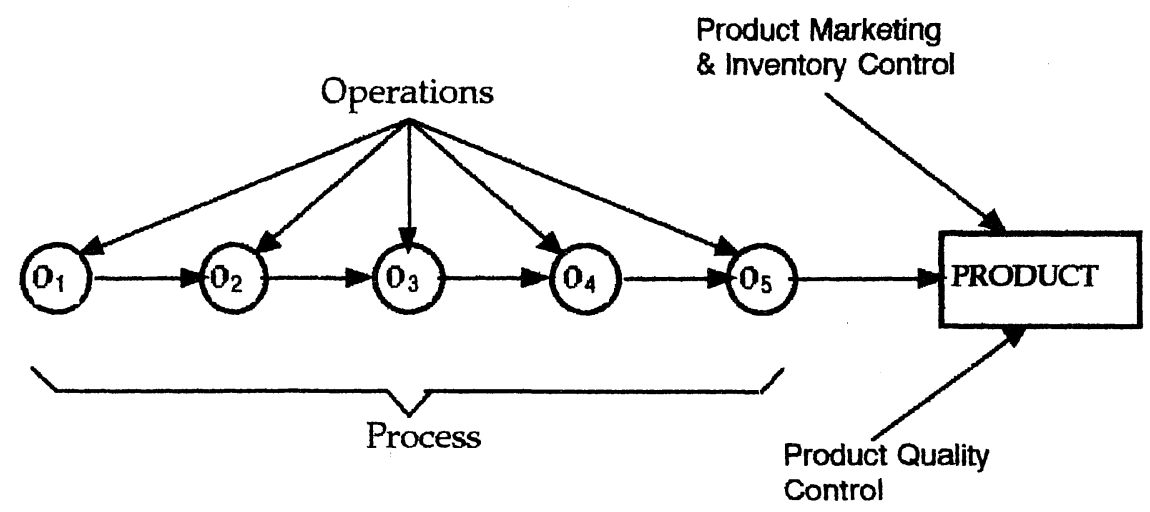

Fig. 1. Relations between product, operations and process.

\section{Business Process Reengineering}

The philosophy of BPR is turning managerial focus and thrust away from the traditional primacy of the final product and the efficacy of operations - towards the process as a fundamental organizational unit, as sketched in Fig. 1.

So, the stage is set for the wedding of the process orientation with the notion of knowledge as a process of coordination of action. Process orientation implies coordination by the 'process owners': individuals, teams, cells, amoebas, etc. Coordinators of action are the possessors of knowledge by definition and Drucker's notion knowledge worker acquires firmer foundations.

Earlier emphasis on isolated parts of the process (product or operation) allowed separation of knowing from doing, rise of command hierarchies and thus relying on symbolic information and its communication up and down the pyramid. Doers did not think and did not know (were not expected to) and thinkers did not do, i.e., did not coordinate action itself and were thus dispossessed of knowledge, although gorging on mountains of symbolic information. They were surely informated, but not knowing.

Not knowing how to do, what to do and why to do things: such state of affairs has become deadly in the era of unforgiving global competition.

\section{Conclusion}

It is now imperative, especially for researchers, management theorists, systems and software developers, etc., to shift their attention from information to knowledge, from symbolic description of action to action itself.

Processing of action rather than information is what the businesses, knowingly or unknowingly, are doing more and more, when undergoing their profound shifts from forecasting to flexibility, from studying 'what they say' to 'what they do', and from relying on product or operations to becoming organizationally rooted in the processes themselves.

The world of action is doing it already. The world aspiring to support and even guide the world of action should start doing it immediately. The punishment would be to remain forever locked in the world of symbolic information processing - an increasingly waning occupation.

Milan Zeleny

Graduate School of Business

Fordham University at Lincoln Center New York, NY 10023

USA 